\title{
0889 IMPACT OF SAFETY PROMOTION AND ENFORCEMENT OF TRAFFIC LEGISLATIONS ON ROAD USERS IN MAURITIUS, 1999-2009
}

S Panchoo* Correspondence: Health and Safety Promotion Network (NGO), 4A De la Tour Road, Vacoas, Mauritius

10.1136/ip.2010.029215.889

Sustained Safety Promotion/Education campaigns among road users and the enforcement of traffic regulations over a period of 20 years have paid dividends in reducing the fatal accidents from 170 in 1999 to 129 in 2009 and the number of fatalities from 170 to 140 during the same period, despite the fact that the number of vehicles has considerably increased during these 11 years. Aggressive road safety promotion campaigns have been conducted during these 11 years by the Ministry of Public Infrastructure, Land Transport \& Shipping, the Road Safety Unit of the Mauritius Police Force and other stakeholders on the use of seat belts and helmets, speeding, drink \& drive and safe behaviour on roads targeting pedestrians, drivers and two wheelers, among others. Moreover, the introduction of the Breath Test/Ethylotest in September 2003 and the speed cameras in December 2008 have played a key role in lowering this number. The number of contraventions established for speeding, non use of seat belts and defective vehicles etc has been on constant rise over the years. Only with the introduction of the mobile speed cameras in 2008, 30000 contraventions have been established. All these measures have to some extent contributed to bring a change in the behaviour of road users who share the same space with high-speed motorised traffic. Better results may be obtained if there is sustainability in the road safety promotion campaigns and in the enforcement of traffic legislations and provision of segregated road space between non-motorised and motorised traffic. 